\title{
Evaluation of humoral immune status in porcine epidemic diarrhea virus (PEDV) infected sows under field conditions
}

\author{
Kang Ouyang 1,2, Duan-Liang Shyu', Santosh Dhakal', Jagadish Hiremath', Basavaraj Binjawadagi', \\ Yashavanth S. Lakshmanappa', Rui Guo ${ }^{3}$, Russell Ransburgh ${ }^{3}$, Kathryn M. Bondra', \\ Phillip Gauger ${ }^{4}$, Jianqiang Zhang ${ }^{4}$, Terry Specht ${ }^{5}$, Aaron Gilbertie ${ }^{5}$, William Minton ${ }^{5}$, Ying Fang ${ }^{3}$ \\ and Gourapura J. Renukaradhya ${ }^{*}$
}

\begin{abstract}
Porcine epidemic diarrhea virus (PEDV) is an economically devastating enteric disease in the swine industry. The virus infects pigs of all ages, but it cause severe clinical disease in neonatal suckling pigs with up to $100 \%$ mortality. Currently, available vaccines are not completely effective and feedback methods utilizing PEDV infected material has variable success in preventing reinfection. Comprehensive information on the levels and duration of effector/memory $\lg A$ and IgG antibody secreting B cell response in the intestines and lymphoid organs of PEDV-infected sows, and their association with specific antibody levels in clinical samples such as plasma, oral fluid, and feces is important. Therefore, our goal in this study was to quantify PEDV specific $\lg A$ and $\lg$ G B cell responses in sows at approximately 1 and 6 months post-infection in commercial swine herds, including parity one and higher sows. Our data indicated that evaluation of both PEDV specific IgA and lgG antibody levels in the plasma and oral fluid (but not feces) samples is beneficial in disease diagnosis. PEDV specific B cell response in the intestine and spleen of infected sows decline by 6 months, and this associates with specific antibody levels in the plasma and oral fluid samples; but the virus neutralization titers in plasma remains high beyond 6 months post-infection. In conclusion, in sows infected with PEDV the presence of effector/memory B cell response and strong virus neutralization titers in plasma up to 6 months postinfection, suggests their potential to protect sows from reinfection and provide maternal immunity to neonates, but challenge studies are required to confirm such responses.
\end{abstract}

\section{Introduction}

Porcine epidemic diarrhea (PED) clinically manifests as severe watery diarrhea with subsequent dehydration in all ages of swine, but highly severe in sucking pigs [1]. Other clinical signs of PED include vomiting and anorexia. PED is characterized by the mortality rate of $30-100 \%$ in neonates, and high morbidity but low mortality in weaned pigs [2]. Economic losses due to elevated mortality and decreased production by PEDV are significant in the US

\footnotetext{
*Correspondence: gourapura.1@osu.edu

${ }^{1}$ Food Animal Health Research Program (FAHRP), OARDC, Department of Veterinary Preventive Medicine, The Ohio State University, Wooster, $\mathrm{OH}$ 44691, USA

Full list of author information is available at the end of the article
}

swine herds. PED virus (PEDV) is the causative agent of PED. PEDV was detected on multiple US swine farms in April of 2013 [1,3], and the virus has continued to spread through swine producing states at an alarming rate until the end of 2014. Over 45779 PEDV tests have been conducted in the US between May 2013 and March 2014, and reported 4757 cases $(\sim 10 \%)$ positive in 27 states [4].

PEDV is an enveloped virus having $28 \mathrm{~kb}$ genome and encode four structural proteins, spike (S), envelope (E), membrane $(\mathrm{M})$, and nucleocapsid $(\mathrm{N})[5,6]$. The $\mathrm{S}$ protein of PEDV is the principle surface glycoprotein involved in virus attachment and entry, and it contains virus-neutralizing B cell epitopes [7-9]. 
PEDV continues to infect naive swine farms breaching strict biosecurity protocols for unknown reasons or has re-infected breeding farms after implementing feedback strategies. Piglets are expected to be protected from the clinical disease through colostral immunity received from immune dams [10]. However, protection from infection and shedding has been variable with occasional failure of feedback regimens. Control and prevention of PEDV is one of the major hurdles to the swine industry in the US.

Currently, available vaccines are not completely effective and feedback methods utilizing PEDV infected material has shown varied success in preventing reinfection. This could be attributed to non-availability of reliable diagnostic tools to monitor the protective herd immune status in sows. Moreover, information about levels and duration of PEDV herd immune status in sows is important to implicate appropriate control measures at verge of disease outbreaks. Therefore, it is critical to develop standardized isotype antibody targeted assays to determine the association of clinical samples data with PEDV specific B cell response at the intestines and lymphoid tissues of sows recovered from PED under field conditions. In this study we quantified both PEDV specific IgA and IgG antibody levels in the clinical samples (plasma, oral fluid, and feces) and associated that to the isotype specific B cell responses in the intestine and lymphoid tissues of PED infected sows in commercial breeding herds of two different parities (primiparous and multiparous).

\section{Materials and methods \\ Cells}

Vero cells (ATCC ${ }^{\circledR}$ CCL-81) were cultured in Minimum Essential Media (Gibco, CA, USA) supplemented with $10 \%$ heat inactivated fetal bovine serum (Atlanta Biologicals, GA, USA), 2 mM L-glutamine (Gibco) and antibiotic/antimycotic solution (HyClone, UT) at $37{ }^{\circ} \mathrm{C}$ in a humidified atmosphere with $5 \% \mathrm{CO}_{2}$. For preparation of virus stocks and in virus neutralizing (VN) assay, the MEM was supplemented with tocylsulfonyl phenylalanyl chloromethyl ketone (TPCK)-trypsin $(1 \mu \mathrm{g} / \mathrm{mL})$ (Sigma, MO, USA), $0.3 \%$ tryptose phosphate broth (Sigma), $0.02 \%$ yeast extract $(\mathrm{BD}, \mathrm{MD})$ and antibiotic/antimycotic solution (HyClone, UT, USA).

\section{Virus}

PEDV strain KS 14-01 was isolated from PED infected field fecal samples at Kansas State University, and was propagated in Vero cells. Confluent cell monolayer was washed with sterile phosphate-buffered saline (PBS) twice before infecting with the virus, and after $1 \mathrm{~h}$ of adsorption at $37{ }^{\circ} \mathrm{C}$ additional infection medium was added without removing the inoculum. The virus induced cytopathogenic effect was reached to approximately $90 \%$ in 2-3 days. The virus culture supernatant was collected after freeze-thawing two times, and then clarified at high speed centrifugation $(3000 \times g$ for $30 \mathrm{~min})$ and purified the viral antigen by ultracentrifugation through a $20 \%$ (wt/vol) sucrose cushion $(100000 \times g$ for $2 \mathrm{~h}$ ). Both the stock virus and viral antigen were stored at $-80{ }^{\circ} \mathrm{C}$ until used. Viral protein concentration was measured by micro BCA protein assay kit (Thermo Scientific, IL, USA) and virus titer was determined by IFA as described previously [11-13].

\section{Animals}

Three swine breeding farms located in the Middle Eastern part of the Unites States were chosen for this study, with the two farms having the history of piglet mortality and laboratory confirmation of PEDV infection by ELISA at approximately 1 and 6 months before necropsy, and the third farm had no history of PED infection. Six sows each from primiparous and multiparous group with a total of 36 sows with the history of PEDV infection or no infection were used in this study (Table 1). Animals were euthanized in a slaughter plant (Bob Evans slaughterhouse, Xenia, Ohio) according to the standard procedures with necessary efforts to minimize suffering of animals. All the procedures on animals used in this study were approved by the Committee on the Ethics of Animal Experiments of The Ohio State University. On the day of necropsy, plasma, oral swab, and fecal samples were collected for virus specific antibody isotype titration; and ileum, mesenteric lymph nodes (MLN), and spleen samples were collected in MEM containing antibiotics and antifungal for isolating mononuclear cells (MNCs).

\section{Isolation of immune cells}

MNCs from ileum, MLN, and spleen were isolated as previously described [14-17] with a few modifications. Briefly, ileum, spleen, and MLN tissues were cut into tiny pieces and only ileum tissues were treated with Type II collagenase after treating with EDTA and dithiothreitol. Cell suspensions were obtained after passing the digested tissues of ileum, spleen, and MLN through stainless steel Cellectors fitted with an $80 \mu \mathrm{m}$ mesh screen (Cellector, FL, USA). The harvested MNCs were subjected to density gradient centrifugation with $43 \%$ and $70 \%$ Percoll, and the cells in the interface were collected and filtered through $40 \mu \mathrm{m}$ cell strainer (BD Falcon, MA, USA) and re-suspended in enriched-RPMI (E-RPMI, RPMI containing 10\% FBS, $200 \mu \mathrm{m}$ HEPES, $1 \mathrm{mM}$ sodium pyruvate, $25 \mu \mathrm{m}$ 2-ME, $1 \mathrm{x}$ non-essential amino acid, and $1 \mathrm{x}$ antibiotic and antifungal). The viability of cells was confirmed by trypan blue dye exclusion method, and counted using a hemocytometer. 
Table 1 Grouping of sows at different stages of PEDV infection.

\begin{tabular}{|c|c|c|c|c|}
\hline Groups & $\begin{array}{l}\text { No. of } \\
\text { sows }\end{array}$ & PEDV infection & Status & Abbreviation \\
\hline 1 & 6 & Mock & Primiparous & Mock-PP \\
\hline 2 & 6 & Mock & Multiparous & Mock-MP \\
\hline 3 & 6 & $\begin{array}{l}1 \text { month post- } \\
\text { infection }\end{array}$ & Primiparous & $1 \mathrm{~m} \mathrm{PI-PP}$ \\
\hline 4 & 6 & $\begin{array}{l}1 \text { month post- } \\
\text { infection }\end{array}$ & Multiparous & $1 \mathrm{~m} \mathrm{Pl-MP}$ \\
\hline 5 & 6 & $\begin{array}{l}6 \text { months post- } \\
\text { infection }\end{array}$ & Primiparous & $6 \mathrm{~m} \mathrm{PI-PP}$ \\
\hline 6 & 6 & $\begin{array}{l}6 \text { months post- } \\
\text { infection }\end{array}$ & Multiparous & $6 \mathrm{~m} \mathrm{Pl-MP}$ \\
\hline
\end{tabular}

A total of 36 sows from three different swine breeding farms located in the Mid-Eastern part of the US, having a clear PEDV infection history (uninfected, 1 month or 6 months post-infected) were selected, and six sows each from primiparous and multiparous groups were transported to a slaughter plant in Ohio. Clinical samples such as blood (plasma), oral fluid, and feces, and tissues of ileum, mesenteric lymph nodes, and spleen were collected on the day of necropsy.

\section{In vitro stimulation of MNCs with PEDV antigen}

MNCs isolated from ileum, MLN, and spleen were plated in 24-well cell culture plate $\left(25 \times 10^{6}\right.$ cells/well $)$ in $2 \mathrm{~mL}$ E-RPMI in the presence of semi-purified PEDV viral antigen $(25 \mu \mathrm{g} / \mathrm{mL})$, and cells treated with medium alone or lipopolysaccharide $(25 \mu \mathrm{g} / \mathrm{mL})$ were included as controls. Cells were cultured for 6 days at $39{ }^{\circ} \mathrm{C}$ with $5 \% \mathrm{CO}_{2}$, and $0.5 \mathrm{~mL}$ of E-RPMI was added to each well on every second day. Supernatants were collected to measure PEDV specific IgA and IgG antibody by ELISA. Cells were harvested, washed using PBS, re-suspended in E-RPMI, counted and used for detecting the population of PEDVspecific IgA and IgG antibody secreting cells (ASC) by enzyme linked immunospot (ELISPOT) assay, and for elucidating the frequency of $\operatorname{IgA}^{+}$and $\operatorname{IgG}^{+} \mathrm{B}$ cells by flow cytometry.

\section{Antibody isotype ELISA}

PEDV specific IgA and IgG antibody levels were determined as described previously $[15,16]$. Briefly, pretitrated amounts of PEDV whole virus-derived antigen $(5 \mu \mathrm{g} / \mathrm{mL})$, recombinant PEDV S protein $(5 \mu \mathrm{g} / \mathrm{mL})$ or $\mathrm{M}$ protein $(10 \mu \mathrm{g} / \mathrm{mL})$ diluted in $50 \mathrm{mM}$ carbonate buffer (pH 9.6) were coated overnight at $4{ }^{\circ} \mathrm{C}$ in the 96-well ELISA plates (Corning, MA, USA). Plates were blocked using 10\% nonfat milk in PBS containing $0.05 \%$ Tween 20. Plasma sample was diluted 1:200, 1:800, 1:3200, and 1:12 800, and oral fluid and fecal samples were diluted $1: 8,1: 32,1: 128$ and 1:512. The supernatants harvested from stimulated MNCs were diluted 1:2 and $50 \mu \mathrm{L}$ of each of the samples was applied into duplicate wells and incubated for $1 \mathrm{~h}$ at room temperature (RT). Plates were washed and horseradish peroxidase-conjugated goat anti-pig IgA (Bethyl laboratories) or IgG antibody (KPL) (1:5000) was added to the plates and incubated for $1 \mathrm{~h}$. The reaction was developed using TMB peroxidase substrate and stopped using $1 \mathrm{M}$ phosphoric acid and plates were read at $\mathrm{OD}_{450}$.

Virus titration and virus neutralizing (VN) antibody assays PEDV titer in stocks and VN antibody titer in clinical samples were analyzed by IFA as described previously [11-13] with a few modifications. Briefly, confluent Vero cell monolayers in 96-well plates were washed once using PBS before seeding the samples. For virus titration, tenfold serially diluted virus stock was added to cells plate in quadruplicate; for VN titration, clinical samples were UV treated (254 $\mathrm{nm}$ for $45 \mathrm{~min}$ ) and heat inactivated $\left(56{ }^{\circ} \mathrm{C}\right.$ for $30 \mathrm{~min}$ ), and twofold serially diluted samples were incubated with equal volume of PEDV (50 TCID ${ }_{50}$ per well) for $1.5 \mathrm{~h}$ at $37^{\circ} \mathrm{C}$, and the mixture was transferred into Vero cells grown in microtiter plates in duplicate. Plates were incubated for $1 \mathrm{~h}$ at $37^{\circ} \mathrm{C}$ and infection medium was added after the wells were washed once using PBS and incubated for $24 \mathrm{~h}$ at $37{ }^{\circ} \mathrm{C}$. Plates were washed and fixed using acetone-Milli- $\mathrm{Q}$ water (8:2) mixture for $10 \mathrm{~min}$ at RT, and dried completely before immunostained. Cells were treated with anti-PEDV N protein specific monoclonal antibody (SD6-29) (Medgene lab, SD, USA) (1:1000) for $2 \mathrm{~h}$ at $37{ }^{\circ} \mathrm{C}$, followed by treatment with Alexa Fluor 488 conjugated goat anti-mouse IgG $(\mathrm{H}+\mathrm{L})$ (Invitrogen, CA, USA) secondary antibody (1:4000). The plate was examined under a fluorescent microscope after mounting with glycerol-PBS (6:4). The virus induced cytopathic effect was examined under a fluorescent microscope, and the titer was calculated using the Reed and Muench method. The viral titer was expressed in $50 \%$ tissue culture infective dose $\left(\mathrm{TCID}_{50}\right)$ per $\mathrm{mL}$. The VN titer was determined to be the reciprocal dilution of plasma/oral fluid/fecal samples that induced greater than $90 \%$ inhibition of viral infection as shown in virus control wells (Figure 2).

\section{Enzyme linked immunospot (ELISPOT) assay for quantifying PEDV-specific ASCs}

ELISPOT assay was performed to analyze the population of PEDV specific IgA and IgG antibody secreting B cells as described previously [14-17] with few modifications. Briefly, two kinds of PEDV whole virus-derived antigen coated plates were used in this study. (i) Vero cells infected and fixed cell culture plates: PEDV $(100 \mu \mathrm{L}$ of $10^{4} \mathrm{TCID}_{50} / \mathrm{mL}$ ) containing $1 \mu \mathrm{g} / \mathrm{mL}$ of TPCK-trypsin was inoculated to confluent Vero cell monolayers in 96-well tissue culture plate. Cells were fixed with $80 \%$ acetone at $16 \mathrm{~h}$ post-infection and plates were stored 
at $-20{ }^{\circ} \mathrm{C}$. At that stage about $80 \%$ of cells were infected as tested by IFA, and the cell monolayer was still intact. Mock-infected cells treated exactly the same way were used as control. (ii) PEDV whole virus-derived antigen immunocaptured plates: Semi-purified viral antigen $(25 \mu \mathrm{g} / \mathrm{mL}$ ) diluted in $50 \mathrm{mM}$ carbonate buffer ( $\mathrm{pH} 9.6)$ was coated overnight at $4{ }^{\circ} \mathrm{C}$ in nitrocellulose-based 96-well microtiter plates (Millipore, MA, USA). Plates were washed with PBS and blocked with E-RPMI for $1 \mathrm{~h}$ at RT and stimulated MNCs of ileum, MLN, and spleen were plated at three tenfold dilutions in duplicate wells starting from $5 \times 10^{5}$ cells/well. All plates were incubated for $16 \mathrm{~h}$ at $39{ }^{\circ} \mathrm{C}$ with $5 \% \mathrm{CO}_{2}$, and washed with PBS containing $0.05 \%$ Tween 20 (PBST). The antibody production was detected using horseradish peroxidaselabeled affinity-purified goat anti-pig IgA (Bethyl laboratories, Texas) or IgG (KPL, Maryland) diluted 1:2000 in PBST and incubated for $2 \mathrm{~h}$ at $37{ }^{\circ} \mathrm{C}$. The color was developed using 3-amino-9-ethylcarbazole substrate (Sigma-Aldrich, St. Louis, USA) and spots were counted using the AID ELISPOT Reader System (Autoimun Diagnostika GmbH Strassberg, Germany). Data were expressed as the mean numbers of ASCs per $5 \times 10^{5}$ MNCs.

\section{Flow cytometric analyses}

The frequencies of $\mathrm{IgA}^{+}$and $\mathrm{IgG}^{+} \mathrm{B}$ cells from 100000 acquired events of immunostained MNCs were determined by flow cytometry as described previously [18] with a few modifications. Briefly, MNCs were stimulated with PEDV whole virus-derived antigen as described above and immunostained with mouse anti-pig IgA mAb (Clone K60 1F1, AbD Serotec) followed by goat antimouse IgG1 conjugated to APC/CY7 and rabbit anti-pig IgG conjugated to Texas Red. Subsequently, cells were fixed, permeabilized and then intracellular stained using FITC conjugated rat anti-mouse CD79 $\beta$ antibody (Clone AT107-2, AbD Serotec), which was shown to cross-react with pig B cells [18]. Cells were acquired using BD Aria II flow cytometer and analyzed using the FlowJo software.

\section{Ethics statement}

This study was carried out in strict accordance with the recommendations by Public Health Service Policy, United States Department of Agriculture Regulations, the National Research Council's Guide for the Care and Use of Laboratory Animals, and the Federation of Animal Science Societies' Guide for the Care and Use of Agricultural Animals in Agricultural Research and Teaching and all the relevant institutional, state, and federal regulations and policies regarding care and use of animals at the Ohio State.

\section{Statistical analysis}

All data were expressed as the mean \pm standard error of mean (SEM) of six sows. Statistical analyses were performed by one-way ANOVA followed by Tukey's post hoc test (GraphPad InStat 5.0 prism software), and the $P$ value of $<0.05$ was considered significant.

\section{Results}

\section{Antibody response in PEDV infected sows}

Details of sow groups used in this study are provided in Table 1. Clinically, sows were healthy before transportation to the slaughter plant at Xenia in Ohio and rested for a day before necropsy. PEDV specific IgA and IgG antibody responses were determined in plasma, oral fluid, and fecal samples using PEDV antigen, recombinant PEDV $S$ and $M$ protein coated plates. Our results indicated PEDV specific IgA antibody response in the samples of plasma (Figure 1A) and oral fluid (Figure 1B) from both one and 6 months post-infected sows was significantly higher than uninfected sows, and a similar trend was present in recombinant $S$ (but not $M$ ) protein coated plates (Figures 1D and E). Surprisingly, in fecal samples the specific IgA antibody against PEDV whole virusderived antigen (Figure $1 C$ ), S protein (Figure 1D), and $M$ protein (Figure 1E) was absent.

Although PEDV specific IgG antibody levels in the plasma of infected sows was significantly higher than uninfected sows (Figures 1F, I and J), the background optical density values of IgG from uninfected sows was higher compared to respective IgA levels (Figures 1A, $D$ and $E$ ). In oral fluid samples of 6 months post PEDVinfected primiparous sows, specific IgG antibody levels against whole viral antigen and recombinant $S$ and $M$ proteins were significantly higher than uninfected and other three infected sow groups (Figures 1G, I and J). PEDV specific IgG antibody in fecal samples was absent in infected sows (Figures $1 \mathrm{H}, \mathrm{I}$ and J). Our data suggests that for diagnostic antibody analysis of PEDV infection in sows, the plasma and oral fluid samples (but not fecal samples) are reliable and consistent.

Further, VN antibody titers against PEDV in infected sow samples were quantified by IFA. For this assay, 50 TCID $_{50}$ of PEDV in each well was used, which showed substantial amount of infected cells at $24 \mathrm{~h}$ post-infection (Figure 2). Our data revealed that in plasma of PEDV uninfected sows, the background VN titer was up to 16 . But, in infected sows, the VN titer was very high in all four infected groups with a titer of 512 (Figure 3A), suggesting that even after 6 months the $\mathrm{VN}$ titer in both primiparous and multiparous sows remained high in the plasma. The VN titers in oral fluid and fecal samples were $\leq 8$ in all the infected sows (Figures $3 \mathrm{~B}$ and $\mathrm{C}$ ). 


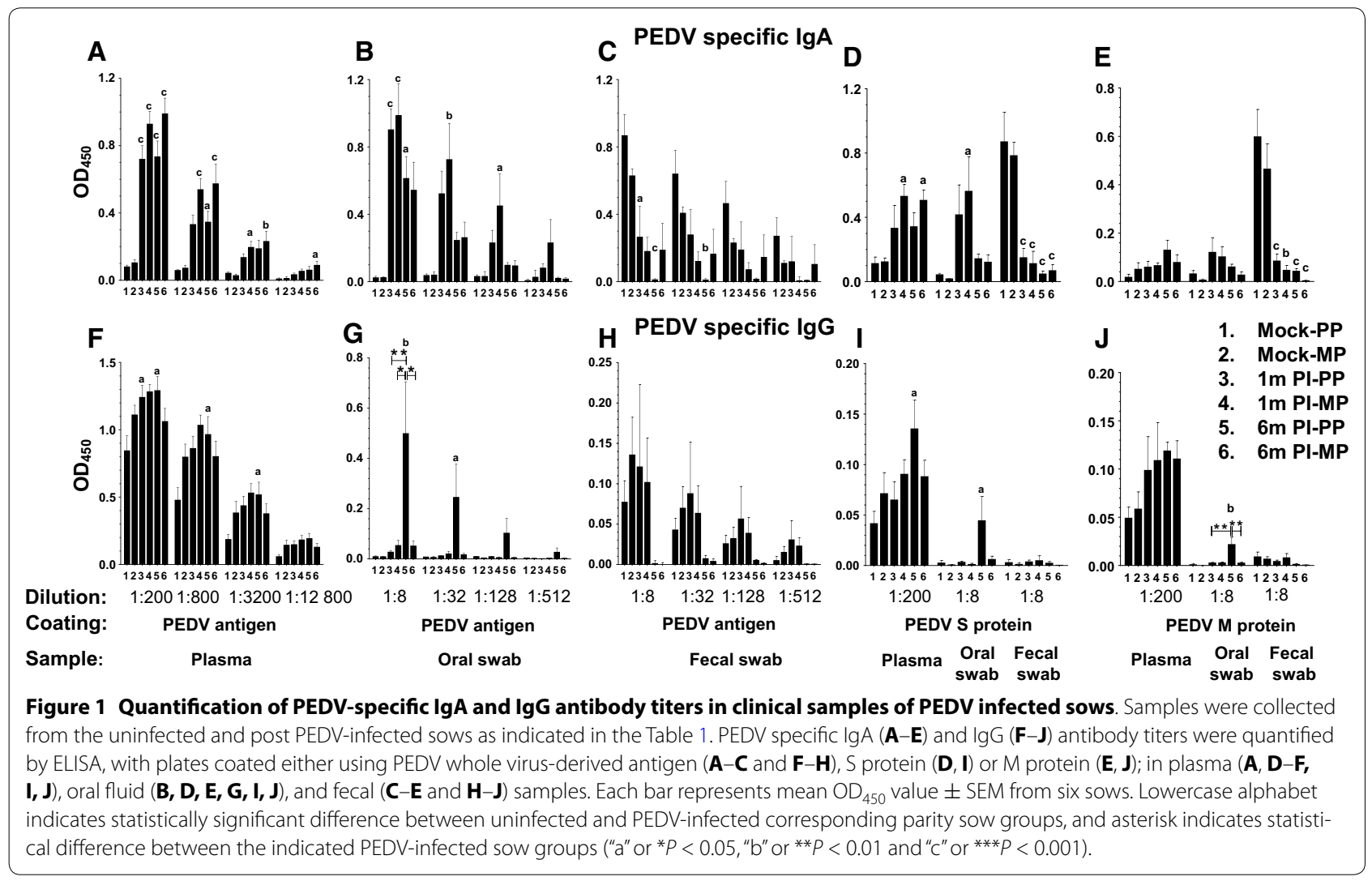

\section{Flow cytometry analysis of PEDV specific IgA and IgG positive $B$ cells in infected sows}

Flow cytometry analysis allows simultaneous multi-parametric analysis of the physical and chemical characteristics of immune cells. MNCs isolated from ileum, MLN, and spleen were stimulated ex vivo using PEDV whole virus-derived antigen for 6 days, and subsequently analyzed the frequency of effector/memory $\operatorname{IgA}^{+}$and $\operatorname{IgG}^{+}$ $B$ cells by flow cytometry. Ileum MNCs of PEDV infected sows stimulated with the virus antigen had significantly higher frequencies of both $\mathrm{CD}^{+} 9^{+} \mathrm{IgA}^{+}$and $\mathrm{CD} 79^{+} \mathrm{IgG}^{+}$ $\mathrm{B}$ cells compared to uninfected sows (Figures $4 \mathrm{~B}$ and $\mathrm{H}$ ). In addition, the frequency of $\mathrm{CD}^{2} 9^{+} \mathrm{IgG}^{+} \mathrm{B}$ cells (but not $\mathrm{CD} 79^{+} \mathrm{IgA}^{+} \mathrm{B}$ cells) were also significantly higher in ileum MNCs unstimulated with medium control of three groups of PEDV infected sows (except 1 month multiparous sows) compared to uninfected sows (Figures $4 \mathrm{~A}$ and G). Specifically, antigen specific $\mathrm{CD}^{+}{ }^{+} \mathrm{IgA}^{+}$and $\mathrm{CD}{ }^{+} \mathrm{IgG}^{+} \mathrm{B}$ cell populations in the ileum of 1 month post PEDV-infected multiparous sows were significantly higher than 6 months post-infected animals with both primiparous and multiparous status (Figures $4 \mathrm{~B}$ and $\mathrm{H})$. However, there was no significant changes in the frequency of both $\mathrm{CD}^{+}{ }^{+} \mathrm{IgA}{ }^{+}$and $\mathrm{CD}^{+} 9^{+} \mathrm{IgG}^{+} \mathrm{B}$ cells in the MLN MNCs of PEDV infected sows, either stimulated with viral antigen (Figures $4 \mathrm{D}$ and $\mathrm{J}$ ) or unstimulated medium control (Figures $4 \mathrm{C}$ and I).

In the spleen of all four post-PEDV-infected sow groups the frequency of $\mathrm{CD}^{+} 9^{+} \operatorname{IgA} \mathrm{A}^{+} \mathrm{B}$ cells was significantly higher compared to their uninfected age-matched counterparts, either unstimulated or stimulated with PEDV whole virus-derived antigen (Figures $4 \mathrm{E}$ and $\mathrm{F}$ ). However, in both primiparous and multiparous sows at 1 month post PEDV-infection, a significantly higher frequency of $\mathrm{CD} 79^{+} \mathrm{IgG}^{+} \mathrm{B}$ cells was observed compared to both uninfected and 6 months post-infected counterparts, either unstimulated or stimulated with PEDV whole virus-derived antigen (Figures $4 \mathrm{~K}$ and L). Further, in the spleen of multiparous sows at 1 month post PEDV-infection, increased frequency of $\mathrm{CD}^{+} 9^{+} \mathrm{IgA}^{+} \mathrm{B}$ cells in unstimulated MNCs was significantly higher than that of primiparous and multiparous sows at 6 months post-infection (Figure 4E). In spleen of primiparous sows at 6 months post PEDV-infection, antigen specific $\mathrm{CD}{ }^{+} \mathrm{IgA}^{+}$memory B cell population in antigen-stimulated splenocytes was significantly less compared to that in multiparous sows at 1 and 6 month post-infection (Figure 4F). Overall, our data indicated that in PEDVinfected multiparous sows, $\mathrm{CD}^{2} 9^{+} \mathrm{IgA}^{+} \mathrm{B}$ cell response is stronger than that of primiparous infected counterpart. 

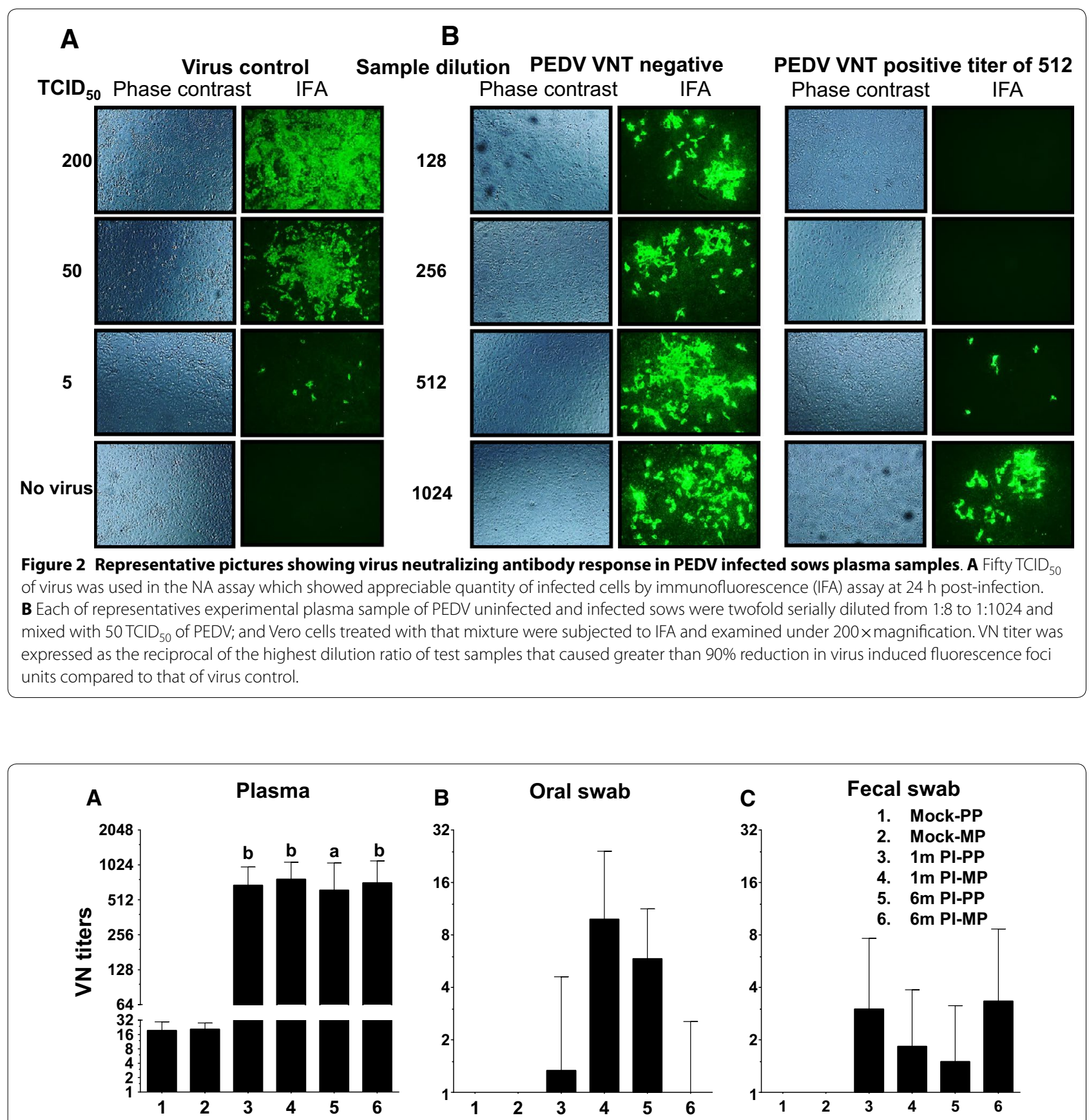

Figure 3 Virus neutralizing antibody titers in PEDV infected sows. (A) Plasma, (B) Oral fluid and (C) fecal samples were analyzed for the VN titers against PEDV by immunofluorescence assay. The VN titer was determined as the reciprocal dilution of the test sample that induced greater than $90 \%$ inhibition of viral infection. Each bar represents mean VN titers \pm SEM from six sows. Lower case alphabet indicates a statistically significant difference ("a" $P<0.05$ and "b" $P<0.01$ ) between mock-uninfected and PEDV-infected corresponding primiparous and multiparous sow groups.

In the culture supernatants harvested at day six cultures of ileum, MLN, and spleen MNCs from multiparous sows at 1 month post-infection, a significantly increased secretion of PEDV specific IgA antibodies specific to the virus was detected (Figure 5A). While in primiparous
PEDV infected sows splenocytes stimulated with antigen, a significantly increased IgA antibody secretion was detected (Figure 5B). While numerically increased (but not significant) trends in IgA antibody production was observed in PEDV infected sows derived MNCs of all 


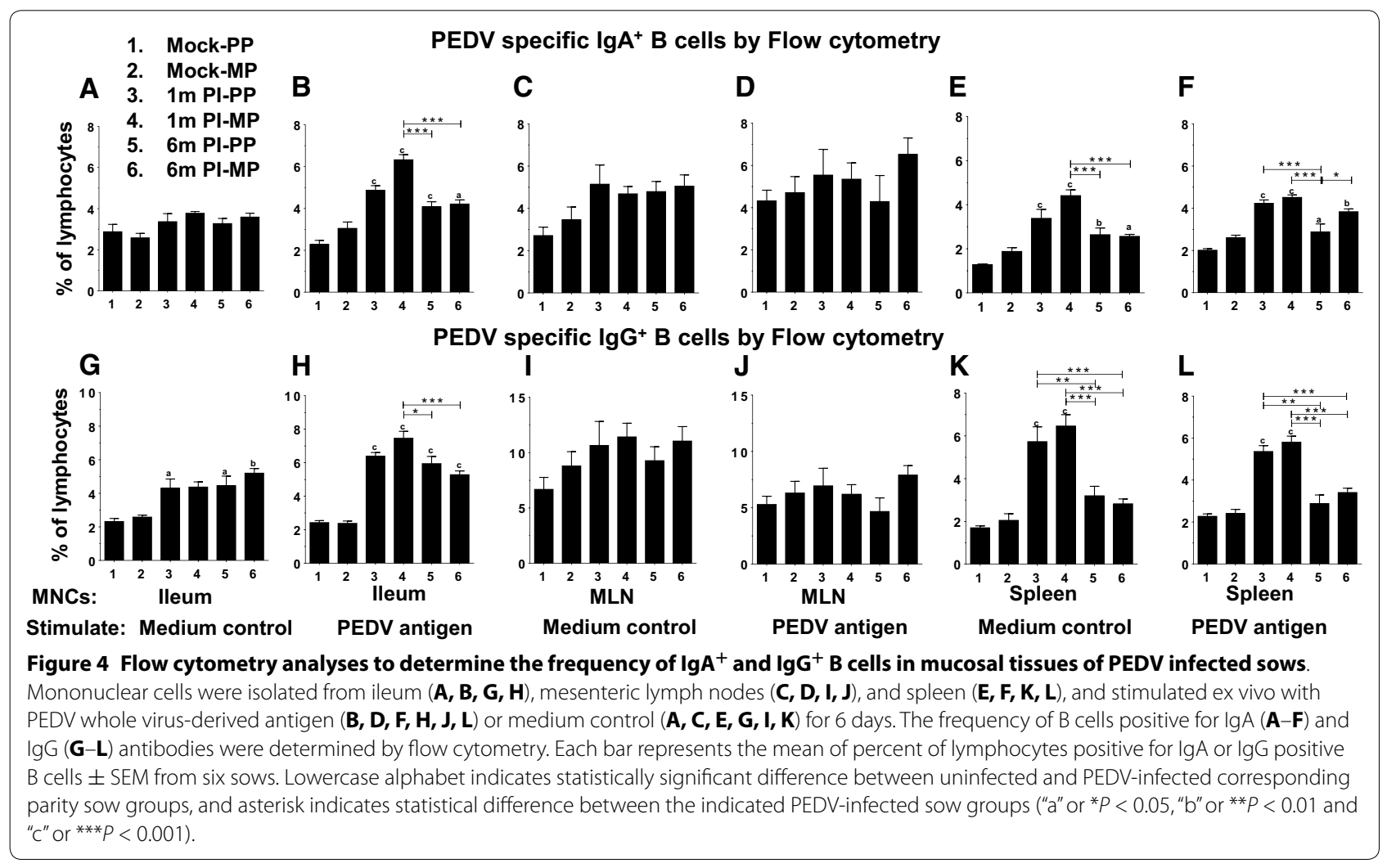

three tissues against the $\mathrm{S}$ protein, and against $\mathrm{M}$ protein the antibody levels were very low (Figures 5C and D). In the splenocytes from primiparous sows at 1 month post PEDV-infection, a significantly higher secretion of virus specific IgG antibodies was detected (Figure 5F).

\section{Quantification of PEDV secreting $\lg A$ and $\lg G$ ASC in infected sows}

ELISPOT assay allows visualization of the secretory product(s) of individual activated cells, and thus provides both qualitative and quantitative information on $\mathrm{T}$ and $\mathrm{B}$ cell responses. Population of PEDV specific IgA and IgG secreting cells (ASCs) present in every 0.5 million MNCs of ileum, MLN and spleen were enumerated by ELISPOT assay (Figure 6). To perform this assay, we used both PEDV whole virus-derived antigen containing fixed Vero cells plate and semi-purified PEDV antigen immunocaptured plate. Both the methods detected similar trend in the frequencies of both IgA and IgG ASCs in PEDV infected sow groups, but in fixed Vero cell antigen coated plates, a fivefold to tenfold higher numbers of ASCs were detected compared to the other, therefore fixed cell antigen plate data is shown here (Figure 6). As expected we did not detect PEDV specific IgA and IgG ASCs in both uninfected primiparous and multiparous sows (Figure 6). Overall, the population of PEDV specific IgA ASCs was greater than IgG ASCs in all three tissue derived MNCs (Figure 6).

In post 1 month PEDV-infected multiparous sows ileum MNCs, cultured for 6 days without any further antigenic stimulation, the number of virus-specific IgA ASCs ( 200) were significantly greater compared to control uninfected and 6 months post PEDV-infected (10 ASCs) sows (Figure 6A); and a similar trend was present in stimulated ileum MNCs (Figure 6B). In contrast, the number of virus-specific IgG ASCs were too low $(<5)$ in the ileum MNCs (Figures 6G and $\mathrm{H}$ ). In MLN MNCs, the number of PEDV-specific IgA ASCs in multiparous sows at 1 and 6 months post PEDV-infection were significantly higher compared to uninfected control sows (Figures 6C and D). In unstimulated MNCs of spleen, frequency of PEDV-specific IgA ASCs ( 400) in all four PEDVinfected sow groups were significantly higher than that from uninfected control sows (Figure 6E); and only in PEDV-infected multiparous sows, a significant increase in IgA ASCs in viral antigen-stimulated MNCs was observed compared to uninfected animals (Figure 6F). However, significantly greater numbers of PEDV-specific IgG ASCs ( 300) were present only in the PEDV whole virus-derived antigen stimulated MNCs from multiparous sows at 1 month post PEDV-infection in comparison to that of uninfected control sows (Figure 6L). 


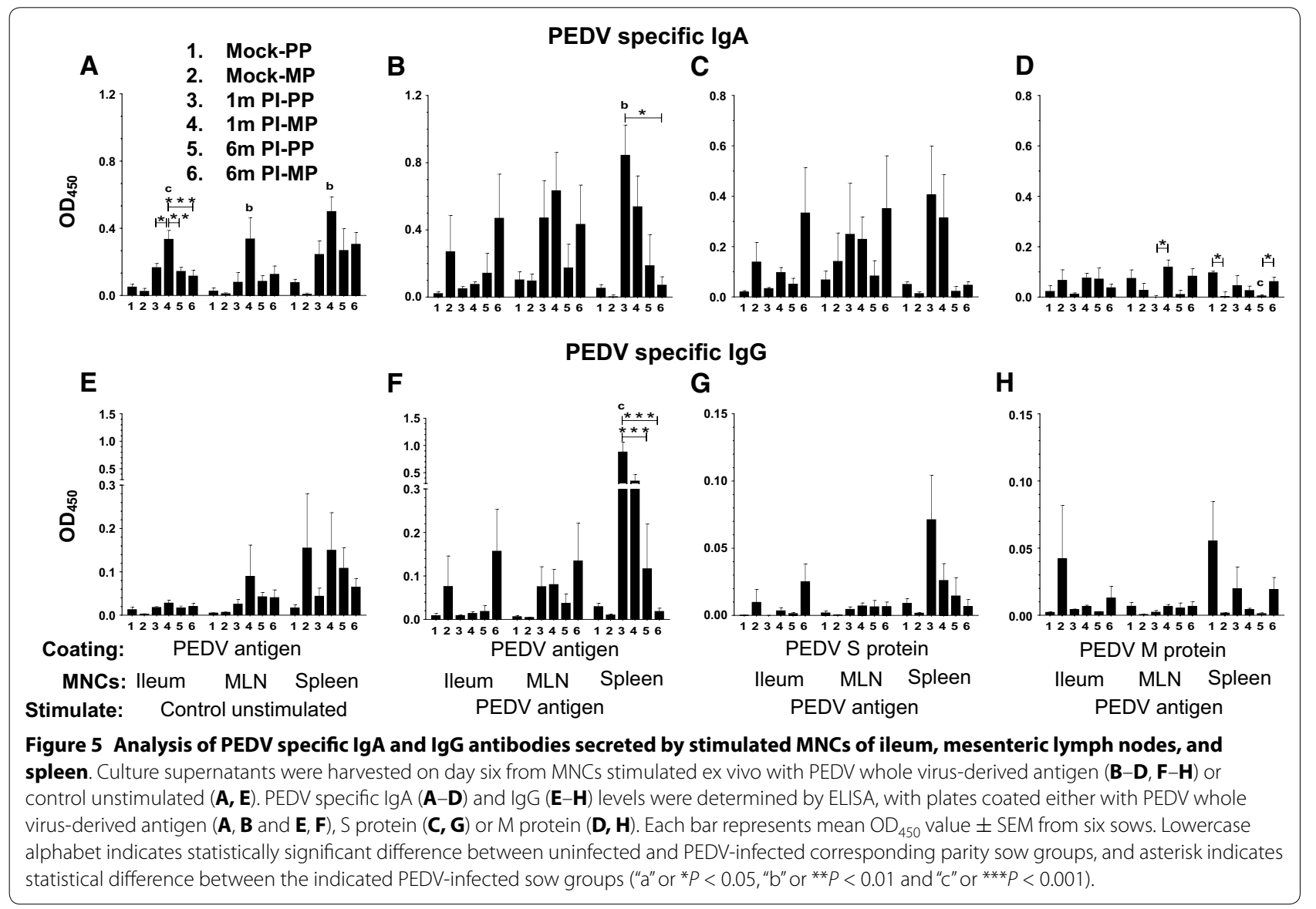

\section{Discussion}

We evaluated PEDV specific B cell response in 24 infected sows at approximate 1 and 6 months post-infection, comprising of both primiparous and multiparous sow groups and included 12 age-matched control uninfected sows. In an earlier study, PEDV whole virus antigen based ELISA was developed using the virus grown in Vero cells, and the viral antigen used in the assay was extracted using $0.2 \%$ Triton X-100 to analyze antibodies in 1024 field samples at the herd level [19]. Though we followed a similar method of growing the virus, but the ELISA antigen was extracted from freeze-thawed viral culture fluid subjected to $20 \%$ sucrose cushion ultracentrifugation, probably the cell debris still present in our antigen preparation would have contributed to the observed high background activity in IgG ELISA in plasma, which needs further investigation.

PEDV S protein is a class I viral fusion protein [20], and is cleaved by host-derived proteases when virus enters the susceptible cell [21]. The S protein contains $B$ cell epitopes for induction of neutralizing antibodies [22]. The S protein-based ELISA was found to be sensitive to evaluate antibody response against PEDV in plasma and colostrum samples [23-26]. In our study, in addition to whole virus antigen, both recombinant PEDV $\mathrm{S}$ and $\mathrm{M}$ protein based IgA and IgG ELISA was used to estimate the levels of antibody in plasma, oral fluid, and fecal samples of sows; and detected high levels of specific IgA response in infected sows' plasma followed by in oral fluid, but not in fecal samples. This suggests that PEDV specific antibodies in the fecal samples of infected sows disappear early (approximately 1-2 months) post-infection; in spite of the presence PEDV specific IgA and IgG ASCs in intestines and lymphoid organs at 6 months post-infection. We also noticed that PEDV specific IgA response in plasma (but not in oral fluid) remained high until 6 months. Furthermore, though we found comparable reactivity of PEDV whole virus derived antigen and S protein for detection of specific IgA antibodies, the antibody levels were twofold less in the $S$ protein based ELISA (ODs at 1:200 dilution). Overall, our data suggested that for diagnosis purpose it is ideal to use both whole virus and S protein based IgA and IgG ELISA in herd oral fluid as well as in statistically acceptable number of plasma samples. 


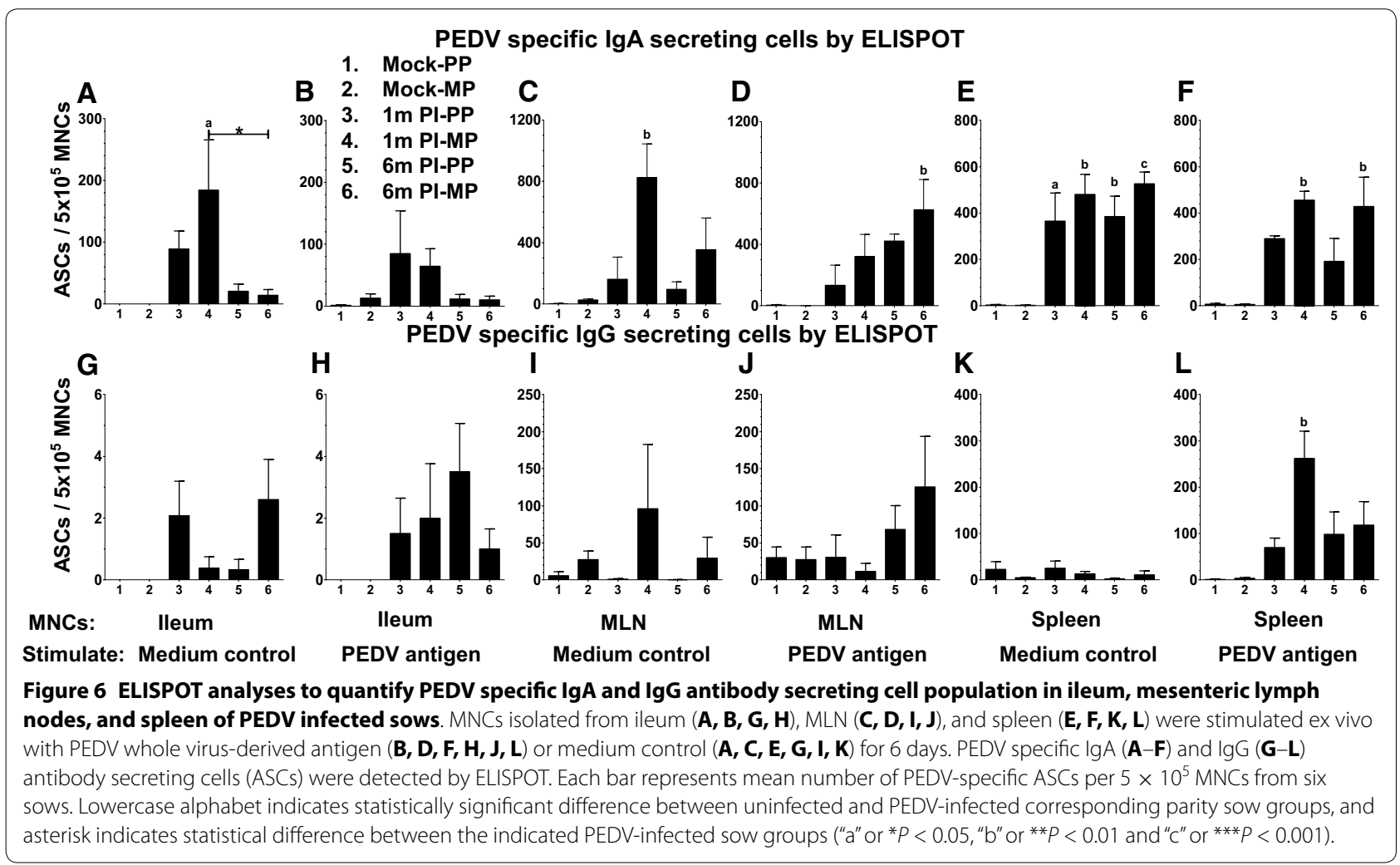

Consistent with the results of others [14, 27, 28], we did not detect PEDV specific response in ileum MNCs of uninfected sows, confirming their PEDV negative status and suggesting the need of in vivo priming of the immune system by the live virus to observe the response. But like earlier results in PEDV infected experimental piglets [16], we observed significantly increased population of PEDV specific ASCs and IgA and IgG positive B cells in the ileum and spleen of sows in in vitro cultured MNCs for 6 days in the absence of viral antigen restimulation, indicating the presence of virus specific effector $B$ cells for up to 6 months in PEDV infected sows. In one of our previous study in pigs vaccinated/infected with porcine reproductive and respiratory syndrome virus a similar recall lymphocyte response in lung MNCs and PBMC cultured in vitro in the absence of the virus antigen was observed $[12,29]$.

Interestingly, we detected substantially higher frequency of PEDV specific ASCs compared to the results of an earlier study [16], this could be attributed to difference in the age of pigs and the virus strain used in the study. At this stage due to lack of pig specific B cell memory marker reagent we could not analyze the frequency of memory $B$ cell pool by flow cytometry in PEDV infected sows.

When PEDV specific IgA and IgG responses in clinical samples were compared with the antibody secreting
B cell population in the ileum, MLN, and spleen of sows analyzed by both flow cytometry and ELISPOT assays; surprisingly, multiparous sows had increased humoral response both in terms of antibody and $B$ cell response compared to primiparous animals, and that response was high in 1 month post-infected sows and declined by 6 months. But the VN titers in plasma remained high in all the PEDV-infected sows, suggesting that infected sows could be resistant to reinfection beyond 6 months. However, the level of protection varies depending on extent of viral antigenic diversity, health status of sows, and secondary microbial infections. Due to lack of virus isolation from PEDV-infected sows, the genetic variability between the virus that infected sows and the virus used for ex vivo stimulation could not be analyzed, and thus we could not determine the levels of cross-protection to PEDV in sows.

In an earlier experimental study, 11 days old conventional pigs were infected with PEDV, and specific IgA and IgG ASCs in the intestines were detected at higher levels than in systemic sites (spleen and PBMC) [16]. However, in sows naturally infected with PEDV, we observed higher levels of IgA and IgG ASCs in spleen than in intestines, suggesting that systemic response is equally important and it persists for longer time in infected sows compared to piglets. Suckling and gnotobiotic pigs infected 
with TGEV and rotavirus, respectively, had higher numbers of specific IgG ASCs compared to IgA ASCs in the intestines [14, 16, 27, 30]. But in our study, in both one and 6 months post PEDV-infected primiparous and multiparous sows, the frequency of specific IgA ASCs were greater than IgG ASCs in the intestines, MLN, and spleen. This suggests the enhanced susceptibility of neonatal pigs to PEDV is responsible for induction of greater levels of IgG ASCs in the intestinal tissues in comparison to that of sows which experience low to mild level of PEDV-infection.

Since PEDV infection is localized to intestinal mucosa, stimulation of systemic immune response especially in piglets is at very low levels [31, 32]. However, our study in sows suggested that systemic response in spleen is predominant over the response in intestines; the differences might be due to time frame of sampling and the age of the animals. Immunologically, the possible reason could be the migration of activated PEDV antigen-bearing dendritic cells to spleen, resulting in activation of naïve $B$ and $\mathrm{T}$ cells. Alternatively, the memory lymphocytes from the mucosa- associated lymphoid tissues could migrate to spleen and bone marrow [33]. In summary, PEDV specific IgA and IgG B cells in infected sows were detectable at higher levels in ileum and spleen compared to that in MLN using both ELISPOT (total B cell response) and flow cytometry (detection of frequency of specific IgA and IgG B cell response) assays, with the later assay demonstrating a more robust result compared to the former in detecting antigen and isotype specific B cells. However, detection of antibody isotype specific B cell response with a memory phenotype marker in mucosal tissues will be highly beneficial to determine PEDV vaccine or infection induced memory in pigs.

In conclusion, our results suggests that detection of PEDV specific IgA in plasma and oral fluid samples has a potential diagnostic implication, and estimation of $\mathrm{VN}$ titers in plasma could serve to determine the protective immune status. Although PEDV specific B cell response decline by 6 months in both ileum and spleen of naturally infected sows, the presence of high levels of $\mathrm{VN}$ titers suggest that such sows may protect their offspring from PEDV infection by genetically closely related virus by up to 6 months.

\section{Competing interests}

The authors declare that they have no competing interests.

\footnotetext{
Author details

${ }^{1}$ Food Animal Health Research Program (FAHRP), OARDC, Department of Vet erinary Preventive Medicine, The Ohio State University, Wooster, OH 44691, USA. ${ }^{2}$ College of Animal Science and Technology, Guangxi University, Nanning, China. ${ }^{3}$ Department of Diagnostic Medicine and Pathobiology, College of Veterinary Medicine, Kansas State University, Manhattan, KS 66506, USA. ${ }^{4}$ Veterinary Diagnostic and Production Animal Medicine, lowa State University, Ames, IA, USA. ${ }^{5}$ Four Star Veterinary Services, Chickasaw, OH 45826, USA.
}

\section{Authors' contributions}

$\mathrm{KO}$ performed the experiments, analysis of data (including statistical analysis) and drafting of the manuscript. DLS, SD, JH, BB, YSL, and KMB performed the experiments. $R G, R R, P G, J Z$, and $Y F$ prepared and provided the reagents exclusively for this research. TS, AG, and WM helped in identifying the infected sow herd performed sample collection. GJR performed the experiments, analysis of data, edited and finalized the manuscript. All authors read and approved the final manuscript.

\section{Acknowledgements}

This work was supported by a grant award from National Pork Board (NPB Project\#14-187). Salaries and research support were also provided by state and federal funds appropriated to Ohio Agricultural Research and Development center, The Ohio State University.

Received: 5 August 2015 Accepted: 17 November 2015

Published online: 14 December 2015

\section{References}

1. Stevenson GW, Hoang H, Schwartz KJ, Burrough ER, Sun D, Madson D, Cooper VL, Pillatzki A, Gauger P, Schmitt BJ, Koster LG, Killian ML, Yoon KJ (2013) Emergence of porcine epidemic diarrhea virus in the United States: clinical signs, lesions, and viral genomic sequences. J Vet Diagn Invest 25:649-654

2. Saif $L J$ (1993) Coronavirus immunogens. Vet Microbiol 37:285-297

3. Huang YW, Dickerman AW, Pineyro P, Li L, Fang L, Kiehne R, Opriessnig T, Meng XJ (2013) Origin, evolution, and genotyping of emergent porcine epidemic diarrhea virus strains in the United States. MBio 4:e00737-e00813

4. The pig site database (2015) http://www.thepigsite.com/swinenews/36126/ped-update-in-us-27-states-affected/. Accessed 23 Nov 2015

5. Pensaert MB, de Bouck P (1978) A new coronavirus-like particle associated with diarrhea in swine. Arch Virol 58:243-247

6. Kocherhans R, Bridgen A, Ackermann M, Tobler K (2001) Completion of the porcine epidemic diarrhoea coronavirus (PEDV) genome sequence. Virus Genes 23:137-144

7. Cruz DJ, Kim CJ, Shin HJ (2008) The GPRLQPY motif located at the carboxy-terminal of the spike protein induces antibodies that neutralize porcine epidemic diarrhea virus. Virus Res 132:192-196

8. Chen J, Liu X, Shi D, Shi H, Zhang X, Li C, Chi Y, Feng L (2013) Detection and molecular diversity of spike gene of porcine epidemic diarrhea virus in China. Viruses 5:2601-2613

9. Sun D, Feng L, Shi H, Chen J, Cui X, Chen H, Liu S, Tong Y, Wang Y, Tong G (2008) Identification of two novel B cell epitopes on porcine epidemic diarrhea virus spike protein. Vet Microbiol 131:73-81

10. Song D, Park B (2012) Porcine epidemic diarrhoea virus: a comprehensive review of molecular epidemiology, diagnosis, and vaccines. Virus Genes 44:167-175

11. Chen Q, Li G, Stasko J, Thomas JT, Stensland WR, Pillatzki AE, Gauger PC, Schwartz KJ, Madson D, Yoon KJ, Stevenson GW, Burrough ER, Harmon KM, Main RG, Zhang J (2014) Isolation and characterization of porcine epidemic diarrhea viruses associated with the 2013 disease outbreak among swine in the United States. J Clin Microbiol 52:234-243

12. Binjawadagi B, Dwivedi V, Manickam C, Ouyang K, Wu Y, Lee LJ, Torrelles JB, Renukaradhya GJ (2014) Adjuvanted poly(lactic-co-glycolic) acid nanoparticle-entrapped inactivated porcine reproductive and respiratory syndrome virus vaccine elicits cross-protective immune response in pigs. Int J Nanomedicine 9:679-694

13. Ouyang K, Binjawadagi B, Kittawornrat A, Olsen C, Hiremath J, Elkalifa N, Schleappi R, Wu J, Zimmerman J, Renukaradhya GJ (2013) Development and validation of an assay to detect porcine reproductive and respiratory syndrome virus-specific neutralizing antibody titers in pig oral fluid samples. Clin Vaccine Immunol 20:1305-1313

14. Yuan L, Ward LA, Rosen BI, To TL, Saif LJ (1996) Systematic and intestinal antibody-secreting cell responses and correlates of protective immunity to human rotavirus in a gnotobiotic pig model of disease. J Virol 70:3075-3083 
15. de Arriba ML, Carvajal A, Pozo J, Rubio P (2002) Mucosal and systemic isotype-specific antibody responses and protection in conventional pigs exposed to virulent or attenuated porcine epidemic diarrhoea virus. Vet Immunol Immunopathol 85:85-97

16. de Arriba ML, Carvajal A, Pozo J, Rubio P (2002) Isotype-specific antibodysecreting cells in systemic and mucosal associated lymphoid tissues and antibody responses in serum of conventional pigs inoculated with PEDV. Vet Immunol Immunopathol 84:1-16

17. Mulupuri P, Zimmerman JJ, Hermann J, Johnson CR, Cano JP, Yu W, Dee SA, Murtaugh MP (2008) Antigen-specific B-cell responses to porcine reproductive and respiratory syndrome virus infection. J Virol 82:358-370

18. Kandasamy S, Chattha KS, Vlasova AN, Saif LJ (2014) Prenatal vitamin A deficiency impairs adaptive immune responses to pentavalent rotavirus vaccine $(\operatorname{RotaTeq}(R))$ in a neonatal gnotobiotic pig model. Vaccine 32:816-824

19. Oh JS, Song DS, Yang JS, Song JY, Moon HJ, Kim TY, Park BK (2005) Comparison of an enzyme-linked immunosorbent assay with serum neutralization test for serodiagnosis of porcine epidemic diarrhea virus infection. J Vet Sci 6:349-352

20. Bosch BJ, van der Zee R, de Haan CA, Rottier PJ (2003) The coronavirus spike protein is a class I virus fusion protein: structural and functional characterization of the fusion core complex. JVirol 77:8801-8811

21. Shirato K, Matsuyama S, Ujike M, Taguchi F (2011) Role of proteases in the release of porcine epidemic diarrhea virus from infected cells. J Virol 85:7872-7880

22. Sun DB, Feng L, Shi HY, Chen JF, Liu SW, Chen HY, Wang YF (2007) Spike protein region (aa 636789) of porcine epidemic diarrhea virus is essential for induction of neutralizing antibodies. Acta Virol 51:149-156

23. Gerber PF, Gong Q, Huang YW, Wang C, Holtkamp D, Opriessnig T (2014) Detection of antibodies against porcine epidemic diarrhea virus in serum and colostrum by indirect ELISA. Vet J 202:33-36

24. Knuchel M, Ackermann M, Muller HK, Kihm U (1992) An ELISA for detection of antibodies against porcine epidemic diarrhoea virus (PEDV) based on the specific solubility of the viral surface glycoprotein. Vet Microbiol 32:117-134
25. Li Y, Zheng F, Fan B, Muhammad HM, Zou Y, Jiang P (2015) Development of an indirect ELISA based on a truncated $S$ protein of the porcine epidemic diarrhea virus. Can J Microbiol 61:811-817

26. Paudel S, Park JE, Jang H, Shin HJ (2014) Comparison of serum neutralization and enzyme-linked immunosorbent assay on sera from porcine epidemic diarrhea virus vaccinated pigs. Vet Q 34:218-223

27. VanCott JL, Brim TA, Simkins RA, Saif LJ (1993) Isotype-specific antibodysecreting cells to transmissible gastroenteritis virus and porcine respiratory coronavirus in gut- and bronchus-associated lymphoid tissues of suckling pigs. J Immunol 150:3990-4000

28. Berthon P, Bernard S, Salmon H, Binns RM (1990) Kinetics of the in vitro antibody response to transmissible gastroenteritis (TGE) virus from pig mesenteric lymph node cells, using the ELISASPOT and ELISA tests. J Immunol Methods 131:173-182

29. Binjawadagi B, Dwivedi V, Manickam C, Ouyang K, Torrelles JB, Renukaradhya GJ (2014) An innovative approach to induce cross-protective immunity against porcine reproductive and respiratory syndrome virus in the lungs of pigs through adjuvanted nanotechnology-based vaccination. Int J Nanomedicine 9:1519-1535

30. Yuan L, Kang SY, Ward LA, To TL, Saif $\sqcup$ (1998) Antibody-secreting cell responses and protective immunity assessed in gnotobiotic pigs inoculated orally or intramuscularly with inactivated human rotavirus. J Virol 72:330-338

31. Ducatelle R, Coussement W, Pensaert MB, Debouck P, Hoorens J (1981) In vivo morphogenesis of a new porcine enteric coronavirus, CV 777. Arch Virol 68:35-44

32. Pensaert MB (1999) Porcine epidemic diarrhea. In: Straw BE et al (eds) Diseases of swine. lowa State Universtiy Press, lowa, pp 179-185

33. Mazo IB, Honczarenko M, Leung H, Cavanagh LL, Bonasio R, Weninger W, Engelke K, Xia L, McEver RP, Koni PA, Silberstein LE, von Andrian UH (2005) Bone marrow is a major reservoir and site of recruitment for central memory CD8 + T cells. Immunity 22:259-270

\section{Submit your next manuscript to BioMed Central and we will help you at every step:}

- We accept pre-submission inquiries

- Our selector tool helps you to find the most relevant journal

- We provide round the clock customer support

- Convenient online submission

- Thorough peer review

- Inclusion in PubMed and all major indexing services

- Maximum visibility for your research

Submit your manuscript at www.biomedcentral.com/submit

\section{() Biomed Central}

